\title{
Design, Experiment and Fabrication of Multipurpose Stretcher for Patients
}

\author{
Arunkumar K N, Charan Kashyap K, Chirag B C, Kausthubh R, Keerthan J
}

\begin{abstract}
A multipurpose stretcher is an advanced stretcher where we can transfer patient from stretcher to bed with minimum human intervention. If we see go by conventional method accidents and comfortless to the patient is more. This paper describes the design and fabrication of a multipurpose Stretcher for patients. We are required to design and create a multipurpose Stretcher which uses gears and belts for lateral movement and hydraulic jacks for adjustment of the height of the beds. The stretcher will be controlled manually with a wheel for lead screw and an extension lever for hydraulic jacks using legs. Currently the stretcher is only designed for linear movement. However, plans to incorporate maneuverability and other functions can beimplemented after the first stage of the development achieves success.
\end{abstract}

Keywords - stretcher, patient transfer, safety.

\section{INTRODUCTION}

Healthcare is a growing industry that is essential to the longevity of humanity. It is an important aspect of everyday life that is always changing and adapting to compete with the everyday changes of the world. The advances in medicine can be as small as the medications developed for treating deceases to the actual equipment monitoring and caring for people. The hospital stretcher or gurney is a piece of equipment used in the health field that may be overlooked at times. Stretchers are a vital piece oflife saving equipment used by paramedic operators. The operator's ability to save a life may falter due to the lack of durability or poor design of a stretcher they are using to transport a patient. In the medical field, this is unacceptable and the potential foraccidents must be reduced. Through the new designing of the stretcher's individual parts and sub- assemblies, the dependability will increase due to a decreased number of potential failure points. The goal of the new design is to maximize stretcher functionality and stretcher depend ability, while increasing comfort for the patient in order to reduce further damage. A stretcher is an apparatus used for moving patients who require medical care. A basic type (cot or litter) must be carried by two or more people. A wheeled stretcher (known as a gurney, trolley, bed or cart) is often equipped with variable height frames, wheels, tracks, or skids. In AmericanEnglish, a wheeled stretcher is referred to

Revised Manuscript Received on April 12, 2019.

Arunkumar K N,Assistant Professor, Department of Mechanical Engineering, Vidyavardhaka College of Engineering.

Charan Kashyap K, Student Scholar Department of Mechanical Engineering, Vidyavardhaka College of Engineering, Mysuru, Karnataka India.

Chirag B C, Student Scholar Department of Mechanical Engineering, Vidyavardhaka College of Engineering, Mysuru, Karnataka India.

Kausthubh R,Student Scholar Department of Mechanical Engineering, Vidyavardhaka College of Engineering, Mysuru, Karnataka India.

Keerthan J, Student Scholar Department of Mechanical Engineering, Vidyavardhaka College of Engineering, Mysuru, Karnataka India. as agurney. Need for patient transfer arrives at various kind of scenario. In different scenario patient is transfer from one surface to the stretcher or to the hospital bed and vice -versa. The initial transfer of patient, which is done by lifting causes lots of injury to patient. In case of the spinal injury the utter care should be taken to transfer patient otherwise it may damage the spinal cord which might become a lifetime injury. Inside the hospital lot of time patient has to be transferred laterally to various department beds for constantly monitoring and checkups.[1] So there must be some transferring aids for easier and safety of patient. These problems have led us to think and come up with a solution of multipurpose stretcher. The idea is that the stretcher will have pneumatic lifts and rollers which help in easy transfer of patient from stretcher to bed or to another stretcher. It can also lift patient from any surface level.

\section{LITERATURE SURVEY}

Trauma is one of the foremost causes of death in children and young adults. A decrease in the time between trauma and hospital arrival has reduced mortality rates Stretchers, chairs, and wheelchairs are the primary means of transporting patients in emergency departments. After a patient arrives in the emergency room, treatment priority is determined using a triage system, and a patient may receive treatment immediately or wait for hours. Thus, emergency department stretchers must be ergonomic, safe, and reliable. Furthermore, it is important that patients can be easily transferred to a stretcher with a minimal amount of movement. Thus, an appropriate stretcher makes the job easier for the emergency medical personnel. Stretchers must serve a number of functions, and several investigations have been undertaken to design ergonomic transport devices. Customer satisfaction is critical for service providers, and the provision of quality products and services is an important way to increase customer satisfaction. Customer demand for quality service has increased competition among service providers, and the demand for quality in the health sector is no different. Emergency departments are the hospital showcase and, as such, their services should be of the highest quality. Stretchers are an indispensable piece of emergency department equipment. Many factors play a role in the choice of stretchers. They can be expensive, particularly with added features in terms of material, utility, ergonomic design, and safety.[2] 
Stretchers, chairs, and wheelchairs are the primary means of transporting patients in emergency departments.

$>$ After a patient arrives in the emergency room, treatment priority is determined using a triage system, and a patient may receive treatment immediately or wait for hours. Thus, emergency department stretchers must be ergonomic, safe, and reliable.

$>$ Furthermore, it is important that patients can be easily transferred to a stretcher with a

minimal amount of movement. Thus, an appropriate stretcher makes the job easier for the emergency medical personnel.

We identified the types (patient, ambulance personnel or other) and number of individuals injured in each adverse event. We classified the injuries as: 1. strain/sprain, 2. Fracture, 3. Laceration or Avulsion,Contusion or abrasion, 5. Death,6. Traumatic brain injury or 7.Other injuries.[3]

\section{STATEMENT OF PROBLEM}

Handling of patients from the stretcher right from Operation Theatre to ward or even while transferring from ambulance to emergency wards has been difficult task when the patients have been severely injured.

Currently patients are being transferred in two ways.

1. Patient is rolled down when patients are conscious.

2. Patient is lifted manually by the caretaker.

3. Patient is lifted using cloth on which patients is lying.

\section{OBJECTIVE}

To understand the present transfer of patient in different conditions. Identify the problems in the present transfer of patient as well as the problems faced by the caretaker. To understand the advantage and disadvantage with the current patient transfer equipment (which is availablein the market).

To reduce the accidents that occurs while transferring the patients from one stretcher toanother.

\section{METHODOLOGY}

\section{Source of Identified Problem (Problem Initiation):}

A friend of us shared his experience about his father during his times in an emergency ward. The patient had undergone a major operation and he was not transferred properly from stretcher to ward bed.

$>$ Another friend shared a similar incident which he experienced where his brother was nothandled properly while transferring to the ward bed from the stretcher. The patient was unaware of what was going on around him as he was under the influence of anesthesia.

$>$ One of our team mates saw an accident on the road and the ambulance personnel did not handle the victim properly while transferring to the stretcher.

All these led to the idea of developing a multipurpose stretcher which could help many patients around the world.

Market Survey (Requirement Analysis):

To know more about stretcher and problems faced by the stretcher we visited Kamakshi Hospital and Sigma Hospital here at Mysore.

$>$ We had a brief talk about our project idea with Administrator of Kamakshi Hospital Dr. K R Kamath. He was impressed with the idea and asked us to get design model, so that they might implement this product in their hospital.

$>$ We talked with patients about the problems they face during their transfer from stretcher to bed and viceversa during our visits to thehospital.

\section{Principle and Construction:}

The design consists of hydraulic jack for up and down movement of the stretcher.

$>$ One more hydraulic jack is provided for the tilting of the stretcher towards the bed side for easy transfer.

$>$ The stretcher is provided with a worm wheel gear box. When the worm wheel is rotated it turns the shafts and the roller belt assembly. Thus, providing the horizontal movement of the bed.

$>$ There are two types of patient transfer incorporated in the design.

a. Type - I Liner transfer Operation: In this there is tilting of the stretcher. It is for light weight patients. Linear movement of bed is performed with worm gears and rollers assembly. Rollers are in turn connected to Belts for smooth movement.

b. Type II patient transfer operation: Thisisforheavier patients. Tilting up of stretcher bed is carried out by hydraulic jack. Linear movement of bed is performed with worm gears and rollers assembly. Rollers are in turn connected to Belts for smooth movement.

\section{Fabrication and Testing:}

The design is converted into real life product with the help of engineering drawings and analysis data done on the product and testing is done on the product by using one of the members of the team as a test subject. The test results are verified with the design and analysis data obtained during the designing phase of the product.

\section{DESIGN CALCULATIONS}

\section{Design of Worm Gear: [4]}

Assumption made,

Worm material: hardened steel

Worm gear Material - Phosphorous Bronze

$\alpha=20^{\circ}$ step involute; $\mathrm{i}=10 \mathrm{a}=80 \mathrm{~mm} ; \mathrm{n}_{2}=120 \mathrm{rpm}$

$\sigma \mathrm{d}$

$=55 \mathrm{~N} / \mathrm{mm} 2$ for phosphorous bronze

$$
\begin{aligned}
& \mathrm{d}_{1}=\frac{\mathrm{a}^{0.875}}{1.466}=60 \mathrm{~mm} \\
& \mathrm{a}=\frac{\mathrm{d}_{1}+\frac{\mathrm{d}_{2}}{2} ; \mathrm{d} \quad 2=240 \mathrm{~mm}}{2}
\end{aligned}
$$




$$
\begin{aligned}
& v_{2}=\frac{\pi \mathrm{d}_{2} \mathrm{n}_{2}}{60000}=1.5 \mathrm{~m} / \mathrm{s} \\
& C_{v}=\frac{6.1}{6.1+\mathrm{v}}=0.802 \\
& b=\frac{a^{0.875}}{2}=45 \mathrm{~mm}
\end{aligned}
$$

ToothLoad, Ft $=$ odCvbYm $=4722.2 \mathrm{~N}$

Dynamic Strength, $=\sigma d b Y m=5888.025 \mathrm{~N}$

$$
\text { WearLoad, } F w=d 2 b k=7419.6 N
$$

Since $F_{w}>F_{s}$ Design is safe

$$
\begin{gathered}
F_{t}=\frac{2 \mathrm{M}_{\mathrm{t}} \mathrm{K}_{\mathrm{l}}}{\mathrm{d}_{2}}, \quad \text { Moment } \mathrm{M}_{\mathrm{t}}=377776 \mathrm{Nmm} \\
M_{t}=\left(\frac{9.55 * 10^{6} * \mathrm{P}}{\text { speed }}\right) ; \text { Power } \mathrm{P}=4.74 \mathrm{KW} \\
\theta=18.67^{\circ}: \mu=0.03832: \gamma=21.8^{\circ} \\
\eta=\frac{\cos \theta-\mu \cot \gamma}{\cos \theta+\mu \cot \gamma}=88.45 \%
\end{gathered}
$$

Assumption made

$$
P=4.74 K ; N=1200 \mathrm{rpm}
$$

$c=550 \mathrm{~m} ;$ pitchdiameter,$d=40 \mathrm{~mm}$

$$
\begin{gathered}
=\frac{\mathrm{n}_{\mathrm{s}}}{\mathrm{n}_{\mathrm{l}}}=1 \\
d=D=40 \mathrm{~mm} \\
v=\frac{\pi \mathrm{d} \mathrm{n}_{\mathrm{s}}}{60000}=2.513 \mathrm{~m} / \mathrm{s}
\end{gathered}
$$

Total Length,

$$
L=2 C+1.57(D+d)+\frac{(D-d)^{2}}{4 C}=1212 \mathrm{~mm}
$$

Nominal Inside Length,

$$
L i=1168 \mathrm{~mm}
$$

Center Distance,

$$
L=2 C+1.57(D+d)=543.2 m m
$$

Power Rating calculated,

$$
\begin{aligned}
& \mathrm{P}=\left(1.08 \gamma^{-0.09}-\frac{69.68}{\mathrm{~d}_{\mathrm{e}}}-1.78 * 10^{-4} \mathrm{~V}^{2}\right) * 0.7355 \mathrm{v} \\
& \mathrm{P}=1.38 \mathrm{KW} \\
& n^{\prime}=\frac{P k_{s}}{(K W) k_{l} k_{a}} \approx 4 \text { belts }
\end{aligned}
$$

Selection criteria,

'B' cross section with Top Width $17 \mathrm{~mm}$ Thickness $11 \mathrm{~mm}$ Nominal Inside length $1168 \mathrm{~mm}$ Number of $\mathrm{V}$ belts is 4

1. Design of Flat Belt: ${ }^{[4]}$

Assumptions made,
Thickness, $=10 ; D=40 \mathrm{~mm} ; d=40 \mathrm{~mm} ; c=550 \mathrm{~mm} ; \mu=$ $0.3 ; n 1=n 2=1200 \mathrm{rpm}$

$$
\begin{array}{r}
\sigma d=\sigma 1=2.5 \mathrm{~N} / \mathrm{mm}^{2} ; \rho=1000 \mathrm{~kg} / \mathrm{m}^{3} \\
\theta_{l}=\pi+2 \sin ^{-1}\left(\frac{-d}{2 C}\right)=3.141 \text { radians }=\theta_{s}
\end{array}
$$

Total Length,

$$
\begin{gathered}
L=\sqrt{4 c^{2}-(D-d)^{2}}+\frac{1}{2}\left(D \theta_{l}+d \theta_{s}\right) \\
=1224.84 \mathrm{~mm} \\
e^{\mu \theta}=2.5658 \\
k=\frac{e^{\mu \theta}-1}{e^{\mu \theta}}=0.61025 \\
v=\frac{\pi(\mathrm{d}+\mathrm{t}) \mathrm{n}_{s}}{60000}=\frac{3.141 \mathrm{~m}}{\mathrm{~s}}
\end{gathered}
$$

Power Transmitted,

$$
P=\frac{b t v}{1000}\left(\sigma-\frac{w v^{2}}{10^{6} g}\right) k ; b=993 \mathrm{~mm}
$$

Stress in the belt due to centrifugal force,

$$
\begin{gathered}
\sigma_{c}=\frac{w v^{2}}{10^{6} \mathrm{~g}}= \\
\frac{\sigma_{1}-\sigma_{\complement}}{\sigma_{2}-\sigma_{c}}=e^{\mu} ; \\
\sigma_{2}=3.47 \mathrm{~N} / \mathrm{mm}^{2} \\
T_{1}=\sigma_{1} A=2475 \mathrm{~N} \\
T_{2}=\sigma_{2} A=3435.3 \mathrm{~N}
\end{gathered}
$$

Length of the belt, $\mathrm{L}=1224.84 \mathrm{~mm}$

Width of belt, $b=99$

Tension, $\mathrm{T} 1=2475 \mathrm{~N}$

$$
\mathrm{T} 2=3435.3 \mathrm{~N}
$$

\section{DESIGN AND ANALYSIS OF STRETCHER}

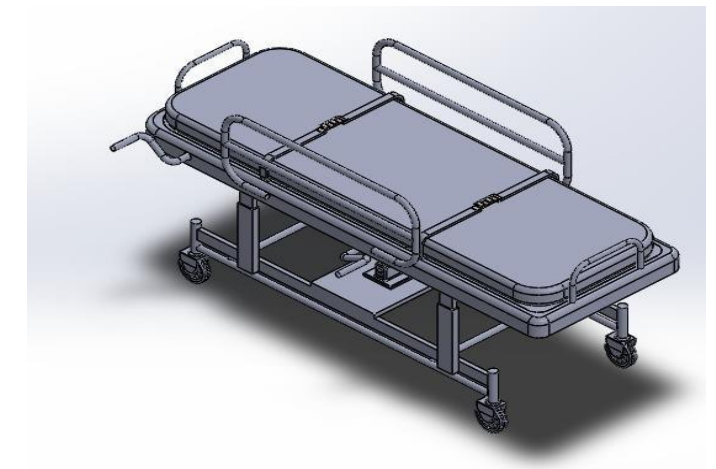

Fig 1. Isometric view

Published By: 


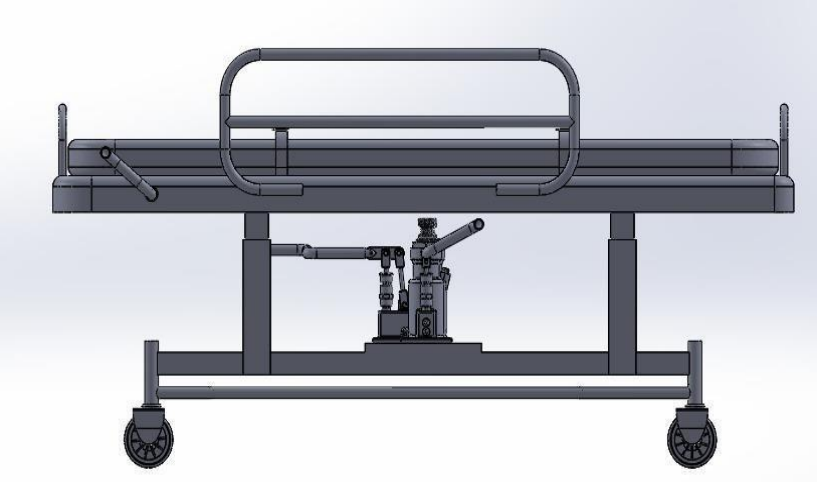

Fig 2. Side View

Analysis helps us to verify the structural integrity of the frame by using the standard values of the material. Theoretical load values are applied on the model at critical points to simulate the amount of force the stretcher would undergo on stretcher along with the patient. Analysis is conducted using Solidworks software where finite element analysis of the stretcher is done.

Mass of the patient is assumed to be $150 \mathrm{~kg}$ Material used AISI 1020 steel, cold rolled

Yield strength: $\quad 3.5 \mathrm{e}+08 \mathrm{~N} / \mathrm{m}^{\wedge} 2$

Tensile strength: $4.2 \mathrm{e}+08 \mathrm{~N} / \mathrm{m}^{\wedge} 2$

Elastic modulus: $2.05 \mathrm{e}+11 \mathrm{~N} / \mathrm{m}^{\wedge} 2$

Poisson's ratio: 0.29

Meshing Details

\begin{tabular}{|l|l|}
\hline Total Nodes & 15344 \\
\hline Total Elements & 7692 \\
\hline Maximum Aspect Ratio & 61.25 \\
\hline \% of elements with Aspect Ratio < 3 & 19.7 \\
\hline \% of elements with Aspect Ratio > 10 & 4.9 \\
\hline
\end{tabular}

\begin{tabular}{|c|c|c|c|}
\hline 2 & mantas-1 & g 3. Solid Me & \\
\hline Von-Mis & s stress Dist & ution & \\
\hline Name & Type & Min & Max \\
\hline Stress & $\begin{array}{l}\text { VON: von } \\
\text { Mises } \\
\text { Stress }\end{array}$ & $\begin{array}{l}4.954 \mathrm{e}+03 \\
\mathrm{~N} / \mathrm{m}^{\wedge} 2 \\
\text { Node: } 3143\end{array}$ & $\begin{array}{l}2.771 \mathrm{e}+06 \\
\mathrm{~N} / \mathrm{m}^{\wedge} 2 \\
\text { Node: } 10010\end{array}$ \\
\hline
\end{tabular}

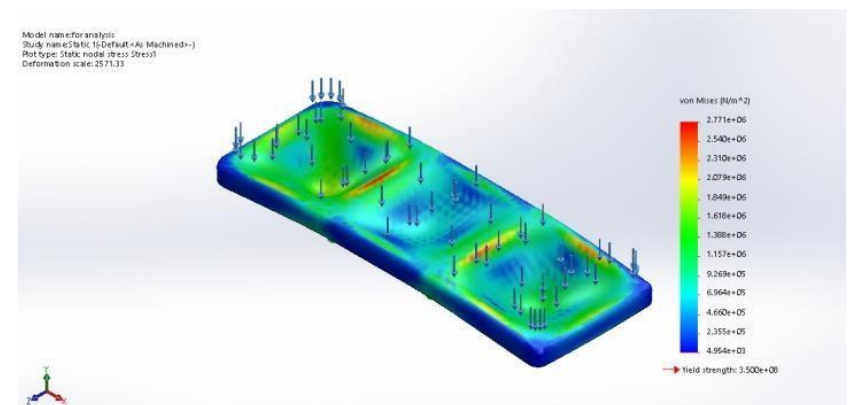

Fig 4. Von-mises stress distribution

Displacement Distribution

\begin{tabular}{|l|l|l|l|}
\hline Name & Type & Min & Max \\
\hline Displacement & URES: & $0.00 \mathrm{e}+00 \mathrm{~mm}$ & $7.424 \mathrm{e}-02 \mathrm{~mm}$ \\
& $\begin{array}{l}\text { Resultant } \\
\text { Displacement }\end{array}$ & Node: 18 & Node: 14968 \\
& & \\
\hline
\end{tabular}

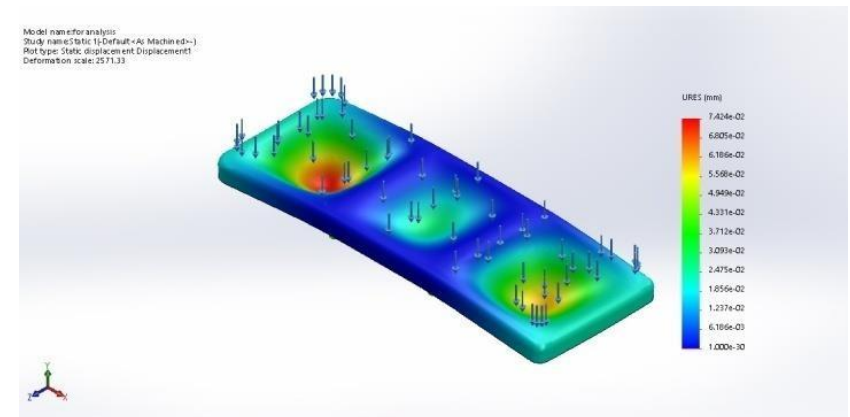

Fig 5. Displacement Distribution

\section{PATIENT TRANSFER}

Type - I Liner transferOperation:

$>$ Linear transfer is carried out by the rotation of the worm, which in turn rotates the worm gear and the shaft rotates.

$>$ As the shaft rotates, the roller turns the $\mathrm{v}$ belt and flat belts on it.

$>$ The rotation of the belts around roller causes the linear motion.

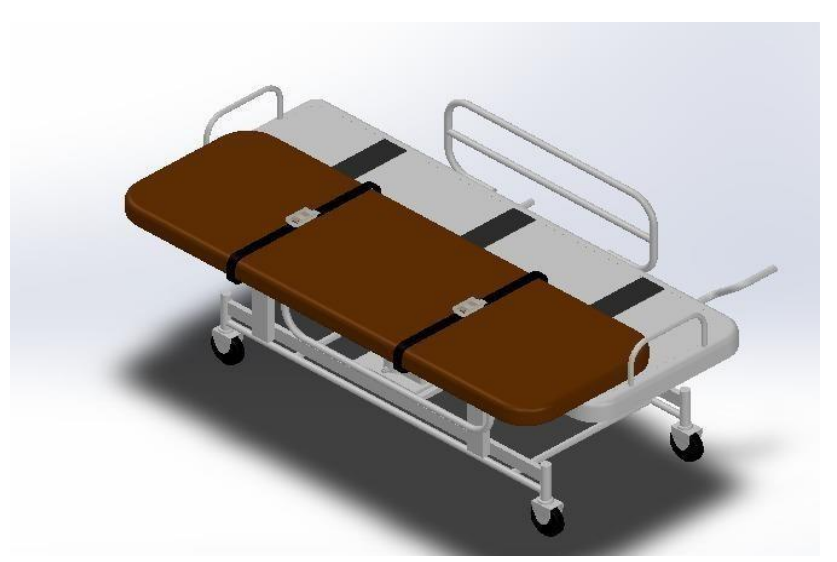

Fig 6. Linear Transfer

Type - II patient transfer operation:

Published By: 
Tilting up of stretcher bed is carried out by hydraulic jack.

$>$ Linear movement of bed is performed with worm gears and rollers assembly.

$>$ Rollers are in turn connected to Belts for smooth movement.

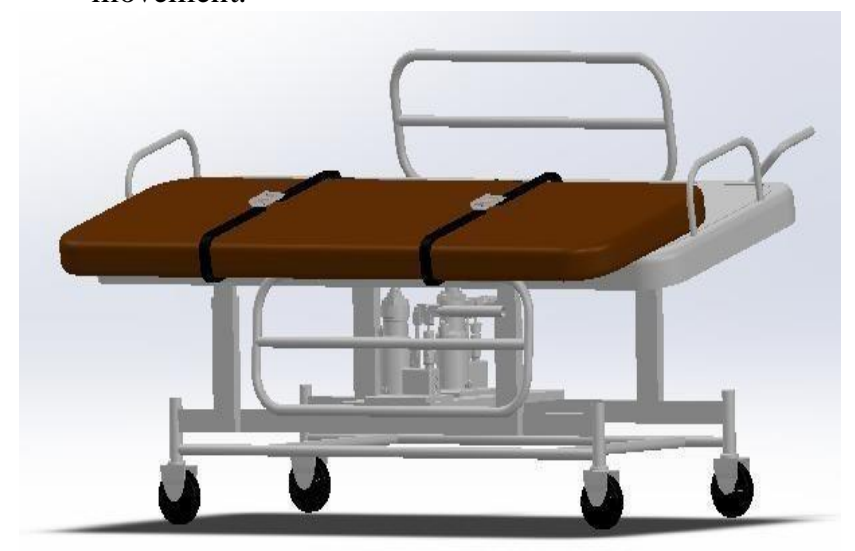

Fig 7. Tilting Action

\section{RESULTS \& DISCUSSION}

Most of the times transferring persons or caretakers are in confusion to transfer patient because the existing transfer system is done by manually or using cloths and also the new equipment's are not used very efficiently. We are developing a system to overcome this confusion and aid in easy transfer of patient.

$>$ While transferring of patients from stretcher to bed or vice versa, injuries happen and which may even aggravate the existing injury or damage. We are developing a stretcher which minimizes or take out such accidents.

\section{SCOPE OF PROJECT}

The transferring device which can be incorporated in all scenarios, i.e. transfer from the accident site or the apartment bed to the stretcher, hospital bed, department bed and vice versa.

$>$ The basic problem of safe and easy transfer of patient from surface to surface will be solved efficiently.

$>$ The device which has included market potential and cope up with the other product available in the market.

\section{CONCLUSION}

Need for patient transfer arrives at various kind of scenario. In different scenario patient is transfer from one surface to the stretcher or to the hospital bed and vice -versa. The initial transfer of patient, which is done by lifting causes lots of injury to patient. In case of the spinal injury the utter care should be taken to transfer patient otherwise it may damage the spinal cord which might become a lifetime injury. Inside the hospital lot of time patient has to be transferred laterally to various department beds for constantly monitoring and checkups. So there must be some transferring aids for easier and safety of patient. These problems have led us to think and come up with a solution of multipurpose stretcher. The idea is that the stretcher will have hydraulic lifts and rollers which help in easy transfer of patient from stretcher to bed or to another stretcher. It can also lift patient to any bed surface level.

$>$ Most of the times transferring persons or caretakers are in confusion to transfer patient because the existing transfer system is done by manually or using cloths and also the new equipment's are not used very efficiently. We are developing a system to overcome this confusion and aid in easy transfer of patient.

$>$ While transferring of patients from stretcher to bed or vice versa, injuries happen and which may even aggravate the existing injury or damage. We are developing a stretcher which minimizes or take out such accidents.

\section{REFERENCES}

1. Neha Bharshankar, guided by Prof.V.PBapat a presentation on "Emergency Patient Transfer System" | Final presentation 28 November,2006

2. Arif DURAN, Hayrettin ÖZTÜRK, ÜmitYaşar TEKELIOĞLU, Tarı OCAK, Mücahit EMET "The Effect of Stretcher Type on Safety and Ease of Treatment in an Emergency Department", Turkish Journal of Medical Sciences(2013)43:986- $\quad$ 989@TÜBİTAKdoi:10.3906/sag1210-51.

3. Wang, Henry \& Weaver, Matthew \& Abo, Benjamin \&Kaliappan, R \& Fairbanks, Rollin. (2009). "Ambulance Stretcher Adverse Events". Quality \& safety in health care. 18. 213-6.10.1136/qshc.2007.024562.

4. K Mahadevan\& K Balaveera Reddy book on "Design Data Handbook for Mechanical Engineers" 4th edition | CBS Publishers \& Distributors Pvt Ltd ISBN:978-81-239-2 